\title{
Insights into modification of lignocellulosic fillers with isophorone diisocyanate: structure, thermal stability and volatile organic compounds emission assessment
}

\author{
Aleksander Hejna ${ }^{1}$ (1) $\cdot$ Mariusz Marć ${ }^{2} \cdot$ Katarzyna Skórczewska $^{3} \cdot$ Joanna Szulc $^{4} \cdot$ Jerzy Korol $^{5} \cdot$ Krzysztof Formela $^{1}$
}

Received: 21 December 2019 / Published online: 4 October 2020

(c) The Author(s) 2020

\begin{abstract}
This study presents an analysis of the structure and properties of different types of lignocellulosic fillers modified by isophorone diisocyanate (IPDI) to provide insights into the possibility of their application to the manufacturing of wood polymer composites (WPCs). Moreover, it deals with the environmental aspects of modified fillers, by assessment of volatile organic compounds (VOCs) emitted during modification, as well as from final products. Three types of commercially available lignocellulosic fillers were modified with different content of IPDI (from 1 to $15 \mathrm{wt} \%$ ) using the internal mixer. The main compounds detected in the air during modifications were terpenes and terpenoids. No IPDI was detected, which is very beneficial considering its toxicity. On the other hand, IPDI was emitted from modified fillers at a slightly elevated temperature of $40^{\circ} \mathrm{C}$, which was associated with a significant rise in its vapor pressure. Successful modification of fillers was confirmed by FTIR spectroscopy and thermogravimetric analysis. Performed modifications of lignocellulosic fillers with IPDI had a relatively small impact on their particle size and color properties. Such an effect can be considered beneficial for the mechanical performance and appearance of WPCs, which could be potentially manufactured using IPDI-modified lignocellulosic fillers.
\end{abstract}

\section{Introduction}

One of the biggest challenges in the manufacturing of wood polymer composites (WPCs) is the improvement of interfacial interactions between hydrophilic lignocellulosic fillers and often hydrophobic polymer matrix, which are crucial for the performance of WPCs. Numerous ways to enhance these interactions have been developed, which often include different filler treatment methods, such as silanization, mercerization, acetylation, maleic anhydride treatment, esterification and etherification, isocyanate grafting, as well as a modification with different surfactants and plasticizers (Błędzki et al. 2008; Colom et al. 2003). Such treatments can significantly improve the characteristics of obtained WPCs. However, they may cause burdens for the environment, for example, due to the use of organic solvents or emission of chemicals during modification and storage of modified fillers (Dányádi et al. 2010). Unfortunately, this issue is usually omitted in the literature.

1 Department of Polymer Technology, Chemical Faculty, Gdańsk University of Technology, G. Narutowicza Str. 11/12, 80-233 Gdańsk, Poland

2 Department of Analytical Chemistry, Gdańsk University of Technology, Narutowicza 11/12, 80-233 Gdańsk, Poland

3 Department of Polymer Technology, University of Science and Technology in Bydgoszcz, Seminaryjna 3, 85-326 Bydgoszcz, Poland

4 Department of Food Industry Technology and Engineering, University of Science and Technology in Bydgoszcz, Seminaryjna 3, 85-326 Bydgoszcz, Poland

5 Department of Material Engineering, Central Mining Institute, Pl. Gwarków 1, 40-166 Katowice, Poland 
Among the applied methods of chemical modification of lignocellulosic fillers, one that is commonly considered as toxic and non-environmentally friendly, is the isocyanate treatment. Isocyanates are very interesting for such applications because they can create stable urethane bonds with hydroxyls present on the surface of lignocellulosic fillers, but also with functional groups present in chains of various polymers such as polyurethanes, poly( $\varepsilon$-caprolactone) or other polar polymers. Because of the high reactivity of free isocyanate groups, they are categorized as irritant, toxic, and hazardous towards humans and the environment (Musk et al. 1988). However, it is only related to their unbonded form, when the isocyanate group is bonded and reacted with other functional groups, for example, hydroxyl or amine groups, no toxic effects are observed. Therefore, it is possible to use polyurethane materials in the manufacturing of biomedical grade articles, such as vascular catheters, blood bags, or implants (Zdrahala and Zdrahala 1999). A similar case is observed for the introduction of isocyanate-modified fillers into WPCs, when the toxic effect should be eliminated (or at least significantly reduced), due to the excess of hydroxyl groups of fillers. Moreover, they are already commonly used in the plastics industry for a very long time. Hence, they are well known and analyzed. As a group, isocyanates have been repeatedly proven as excellent coupling agents for polyolefin-based biocomposites, providing properties superior to those compatibilized with anhydrides or silanes (Ashori and Nourbakhsh 2009; Geng et al. 2005).

One of the first works related to filler modification with isocyanates was published about 20 years ago by the research group of Maldas et al. (Maldas et al. 1988, 1989; Raj et al. 1989, 1990), who investigated the modification of wood sawdust and various types of pulps from paper industry with the most popular isocyanates - toluene diisocyanate (TDI), hexamethylene diisocyanate (HDI) and polymeric methylene diphenyl diisocyanate (pMDI). For the last one, the authors noted a $20 \%$ increase in tensile strength and $40 \%$ enhancement of Young's modulus, when modified fillers were introduced into a polystyrene matrix. Similar observations were noted for polyethylene when modification with pMDI was found to be more effective than the silanization of fillers.

Next, for two decades various research groups investigated the application of other isocyanates, including the isophorone diisocyanate (IPDI) (Girouard et al. 2016), phenylbutyl isocyanate (Morelli et al. 2015) or urethane derivative of cardanol obtained by mixing of cardanol with an excess of TDI (Joseph et al. 1995, 1996; Paul et al. 1997). Other researchers introduced catalysts aimed at the enhancement of modification efficiency (Gómez-Fernández et al. 2017; Nair and Thomas 2003). However, these works mainly focused on the modified fillers' impact on WPCs properties, without the analysis of their environmental impact. Nevertheless, health and safety issues should also be addressed, which will enable the optimization of fillers' modification and development of more environmentally friendly processes in the future (Doustmohammadi and Babazadeh 2019; Keskisaari and Kärki 2016; Quitadamo et al. 2019).

In the present work, the influence of isophorone diisocyanate treatment on the performance of three types of commercially available lignocellulosic fillers was analyzed. The application of this compound as a modifier for natural fillers has hardly been analyzed in the literature. Simultaneously, screening studies were performed to investigate the VOCs emitted during the filler modification process, as well as total volatile organic compounds (VOCs) released to the gaseous phase from IPDI-modified lignocellulosic fillers. Moreover, chemical structure, color, and thermal stability of isophorone diisocyanate treated lignocellulosic fillers were investigated. The comprehensive analytical information about volatile organic compounds emitted from isophorone diisocyanate-modified lignocellulosic fillers gives insight and new knowledge of this approach of fillers functionalization by isocyanates and their further impact on potential applications.

\section{Experimental}

\subsection{Materials}

Three types of commercially available Arbocel@ fillers from JRS J. Rettenmaier \& Söhne GmbH (Germany) were used in the present study: B400, CW630PU, and UFC100. In Table 1, the properties of the applied fillers are listed and Fig. 1 shows microscopic images of the applied fillers.

Fillers were modified with isophorone diisocyanate characterized by a content of isocyanate groups of $37.5 \%$. IPDI was acquired from Merck Millipore.

\subsection{Modification of fillers}

Fillers were modified using GMF 106/2 Brabender batch mixer at room temperature (varied from 21.1 to $23.1{ }^{\circ} \mathrm{C}$ ) and rotor speed of $100 \mathrm{rpm}$. Room temperature was applied

Table 1 Properties of applied Arbocel ${ }^{\circledR}$ fillers

\begin{tabular}{llll}
\hline Filler type & B400 & CW630PU & UFC100 \\
\hline Whiteness, \% & 86 & 60 & 85 \\
Average particle length, $\mu \mathrm{m}$ & 900 & 40 & 8 \\
Average particle thickness, $\mu \mathrm{m}$ & 20 & 20 & 2 \\
Aspect ratio L/D & 45 & 2 & 4 \\
Bulk density, g/l & 30 & 205 & 160 \\
Moisture content, wt\% & 6.01 & 6.81 & 4.84 \\
\hline
\end{tabular}




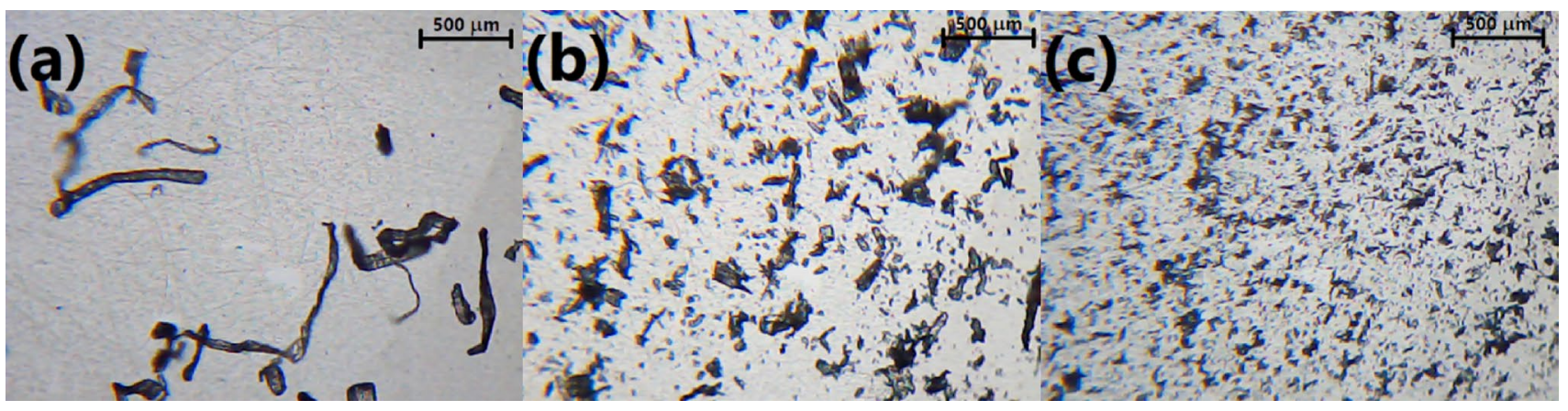

Fig. 1 Microscopic images of applied lignocellulosic Arbocel® fillers: a B400, b CW630PU and c UFC100 at $40 \times$ magnification

to reduce the possible emissions from an applied diisocyanate, which at $20^{\circ} \mathrm{C}$ shows relatively low volatility-vapor pressure equals $4.0 \times 10^{-2} \mathrm{~Pa}$. At higher temperatures, its volatility significantly increases. When the temperature is elevated to $50{ }^{\circ} \mathrm{C}$, the vapor pressure is increased 22.5 times. A proper amount of fillers was placed in an internal mixer (amount varied for different fillers, which was associated with different densities) with a calculated amount of isocyanate $-0 ; 1.0 ; 2.5 ; 5.0 ; 10.0$ or $15.0 \mathrm{wt} \%$ respectively to the mass of fillers. Mixing was performed for $5 \mathrm{~min}$. Then, the samples were put in zipper storage bags.

\subsection{Measurements and analyte sampling equipment}

The air quality screening studies performed in an enclosed area were carried out with the use of Radiello $₫$ diffusive passive samplers (Fondazione Salvatore Maugeri, Padova, Italy). The application of a passive sampling technique facilitates collection of the analytes from the gaseous phase without any additional equipment such as aspirators, pumps, or additional gas wires, which allows performing the research without disturbing the regular use of defined enclosed area or working place. Detailed information about the characteristics and technical parameters of the Radiello ${ }^{\circledR}$ diffusive passive sampler is listed elsewhere (Marć et al. 2014a, b; Plaisance et al. 2008). In brief, the exposure time of applied passive samplers in enclosed space was set up to $4 \mathrm{~h}$. The short sampling period was associated mainly with the indoor environment conditions (the possibility of high or very high content level of organic compounds in gaseous phase due to the specific character of the indoor sampling area that might "overload" the sorption medium installed inside the diffusive porous polyethylene membrane). Each time, two independent Radiello ${ }^{\circledR}$ passive samplers were installed, at a distance of more than $1 \mathrm{~m}$ to ensure optimal conditions for collecting analytes from the gaseous phase (adequate air circulation around the passive sampler, as well as avoiding the phenomenon of competitiveness between installed passive samplers). The passive samplers were installed very close to the workplace and in close vicinity to the materials preparation area. During the passive sampling working period, the temperature inside the studied area was constantly monitored and was in the range from 21.1 up to $23.1{ }^{\circ} \mathrm{C}$. After the sampling period, the cylindrical tubes with sorption medium (Carbotrap 4) were removed from the diffusive membrane and enclosed in the glass containers. Next, the sorption medium with adsorbed analytes was transported to the laboratory and stored at a temperature of $4{ }^{\circ} \mathrm{C}$ no longer than $12 \mathrm{~h}$ after sampling. The identification of the main volatile organic compounds in the air of the enclosed space was performed with the use of thermal desorption technique (Unity v.2, Markes International Ltd., Pontyclun, UK), connected with gas chromatography (Agilent Technologies 6890) combined with a mass spectrometer (5873 Network Mass Selective Detector, Agilent Technologies). The cylindrical containers filled with sorption medium were desorbed at a temperature of $290{ }^{\circ} \mathrm{C}$ for $15 \mathrm{~min}$. During this process, the analytes were transported to the microtrap. Then, the analytes were liberated from the microtrap (ballistic heating up to $300{ }^{\circ} \mathrm{C}$ and maintained for $5 \mathrm{~min}$ ) and transported by the helium flow $\left(1.5 \mathrm{~mL} \mathrm{~min}^{-1}\right)$ to the GC capillary column (Agilent $122-5563$, J\&W DB-5MS, $60 \mathrm{~m} \times 0.25 \mathrm{~mm} \times 1 \mu \mathrm{m})$. The $\mathrm{GC}$ oven temperature program was as follows: $50^{\circ} \mathrm{C}$ for $1 \mathrm{~min}$, then raised at a rate of $10{ }^{\circ} \mathrm{C} \mathrm{min}-1$ up to $280{ }^{\circ} \mathrm{C}$ and maintained for $10 \mathrm{~min}$. The temperature of the TD-GC transfer line was set to $150{ }^{\circ} \mathrm{C}$, and the temperature of the GC-MS transfer line was $280^{\circ} \mathrm{C}$. The employed mass spectrometer was working in a SCAN mode. Detailed information about the principals and characteristic of the thermal desorption technique is presented elsewhere (Król et al. 2012; Zabiegała et al. 2007). To eliminate signals associated with other processes occurring in the laboratory hall and select only signals related to the performed modification, as well as to ensure the reliability of obtained results, the "background" was also analyzed. Additionally, 
before each sampling period, the sorption medium placed in the cylindrical tube was conditioned for $30 \mathrm{~min}$ at a temperature of $300{ }^{\circ} \mathrm{C}$.

The emission studies (expressed by TVOCs parameter) were performed using the microscale stationary emission chamber system (Markes International Micro-Chamber/ Thermal Extractor M-CTE250) consisting of four stainless steel chambers with the internal volume of $114 \mathrm{~cm}^{3}$. Detailed information about the characteristic of the stationary emission chamber system is described elsewhere (Marć and Zabiegała 2017; Marć et al. 2017). In brief, the sample of modified lignocellulosic fillers (mass of a sample-1.073 $\pm 0.059 \mathrm{~g}$ ) was firstly placed on a Petri glass dish and then installed inside the chamber to prevent chamber contamination with small particles of solid samples. Next, the chambers were tightly closed, and at the head of the cover, the stainless steel tube filled with sorption medium Tenax TA was installed to collect the analytes emitted from the surface of the studied samples to the gaseous phase. Then, the sampling conditions were set: samples seasoning time-20 min; inert gas (nitrogen) flow rate $-15 \mathrm{~mL} \mathrm{~min}^{-1}$; seasoning temperature $-40{ }^{\circ} \mathrm{C}$. After the sampling process, the stainless steel tubes were removed and transferred directly to the thermal desorber (Mareks Int, Unity 2) connected with gas chromatograph (Agilent Technologies 7820A) combined with flame ionization detector. The stainless steel tubes filled with Tenax TA were desorbed at a temperature of $285{ }^{\circ} \mathrm{C}$ for $12 \mathrm{~min}$. During this process, the analytes were transported to the microtrap. Then, similar to the TD-GC-MS system, the analytes were liberated from the microtrap (ballistic heating up to $300^{\circ} \mathrm{C}$ and maintained for $5 \mathrm{~min}$ ) and transported by the helium flow $\left(2.0 \mathrm{~mL} \mathrm{~min}{ }^{-1}\right)$ to the GC capillary column (J\&W, DB- $1,30 \mathrm{~m} \times 0.32 \mathrm{~mm} \times 5 \mu \mathrm{m}$ ). The GC oven temperature program was as follows: $45^{\circ} \mathrm{C}$ for $1 \mathrm{~min}$, then raised at a rate of $15{ }^{\circ} \mathrm{C} \mathrm{min}-1$ up to $120^{\circ} \mathrm{C}$ maintained for $2 \mathrm{~min}$, and then raised at a rate of $10^{\circ} \mathrm{C}$ up to $250^{\circ} \mathrm{C}$ and held for $5 \mathrm{~min}$. The temperature of the TD-GC transfer line was set to $160{ }^{\circ} \mathrm{C}$, and the FID temperature was $250{ }^{\circ} \mathrm{C}$. Before every sampling period, the chambers with the glass Petri dish inlet were conditioned at a temperature of $100{ }^{\circ} \mathrm{C}$ for $30 \mathrm{~min}$, and the blank sample (background value) was measured to ensure the reliability of the obtained results. Additionally, before each sampling period, the Tenax TA stainless steel tubes were conditioned for $30 \mathrm{~min}$ at a temperature of $300^{\circ} \mathrm{C}$. The most important information about the calibration process of the mentioned TD-GC-FID system and the assessment of the basic validation parameters is described in detail in previous papers (Marć and Zabiegała 2017; Marć et al. 2017). The values of the TVOC parameter were assessed based on the toluene equivalent. The recovery values of toluene from the applied Tenax TA sorption resin ranged from 95 up to $105 \%$. As for the LOD, the value of this parameter was estimated based on the characteristic of the prepared calibration curve.
The calculated value of LOD for toluene was $0.040 \mathrm{ng}$, and the $\mathrm{LOQ}$ value $(3 \times \mathrm{LOD})$ was $0.12 \mathrm{ng}$.

The particle size distribution of modified lignocellulosic fillers was characterized using a laser particle sizer Fritsch ANALYSETTE 22 apparatus operated in the range of 0.08-2000 $\mu \mathrm{m}$.

Scanning electron microscopy (SEM) was applied in order to evaluate the changes on the fillers' surface as a result of performed modifications. The scanning electron microscope (SEM) - model MIRA3 - from Tescan (Brno, Czech Republic), was used to assess the structure of the external and internal surfaces of the rotationally molded products. The structures of the surfaces of the rotationally molded samples were assessed at an accelerating voltage of $1 \mathrm{kV}$.

The chemical structure of lignocellulosic fillers' samples was determined using Fourier transform infrared spectroscopy (FTIR) analysis performed by a Nicolet Spectrometer IR200 from Thermo Scientific (USA). The device had ATR attachment with a diamond crystal. Measurements were taken with $1 \mathrm{~cm}^{-1}$ resolution in the range from 4000 to $400 \mathrm{~cm}^{-1}$ and 64 scans.

The color of ground organic powders was evaluated according to the Commission Internationale de l'Eclairage (CIE) through L*a*b* coordinates (International Commission on Illumination 1978). In this system, $\mathrm{L}^{*}$ is the color lightness ( $\mathrm{L}^{*}=0$ for black and $\mathrm{L}^{*}=100$ for white), $\mathrm{a}^{*}$ is the green $(-) /$ red (+) axis, and $b^{*}$ is the blue $(-) / y e l l o w(+)$ axis. Thirty tests of each sample were done and used for the determination of arithmetic mean values. The color was determined by optical spectroscopy using HunterLab Miniscan MS/S-4000S spectrophotometer, placed additionally in a specially designed light trap chamber. The total color difference parameter $\left(\Delta \mathrm{E}^{*}\right)$ was calculated according to the following formulation (1) (Bociaga and Trzaskalska 2016):

$\Delta E^{*}=\left[\left(\Delta L^{*}\right)^{2}+\left(\Delta a^{*}\right)^{2}+\left(\Delta b^{*}\right)^{2}\right]^{0.5}$

The thermal analysis was performed using the TG 209 F3 apparatus from Netzsch (Germany). Samples of fillers weighing approximately $10 \mathrm{mg}$ were placed in a ceramic dish. The study was conducted in an inert gas atmosphere-nitrogen in the range from 30 to $900{ }^{\circ} \mathrm{C}$ with a temperature increase rate of $10^{\circ} \mathrm{C} \mathrm{min}^{-1}$. Two specimens were analyzed for each sample.

\section{Results and discussion}

\subsection{VOCs emission during filler modification}

Determination of volatile organic compounds emissions during various chemical processes is essential for human safety, though not very often investigated and described in 
Table 2 Main chemical compounds detected during modification of lignocellulosic fillers

\begin{tabular}{|c|c|c|c|c|c|c|c|}
\hline \multirow[t]{2}{*}{ Compound } & \multirow[t]{2}{*}{ Formula } & \multirow[t]{2}{*}{ Chemical structure } & \multirow{2}{*}{$\begin{array}{c}\text { Flash } \\
\text { point, }{ }^{\circ} \mathrm{C}\end{array}$} & \multicolumn{3}{|c|}{$\begin{array}{c}\text { NFPA } 704 \\
\text { codes }\end{array}$} & \multirow{2}{*}{$\begin{array}{c}\text { GHS } \\
\text { pictograms }\end{array}$} \\
\hline & & & & $\mathrm{F}$ & $\mathrm{H}$ & I & \\
\hline Octanal & $\mathrm{C}_{8} \mathrm{H}_{16} \mathrm{O}$ & & 51 & 2 & 0 & 0 & \\
\hline$o$-Cymene & $\mathrm{C}_{10} \mathrm{H}_{14}$ & & 50 & 2 & 1 & 0 & \\
\hline$m$-Cymene & $\mathrm{C}_{10} \mathrm{H}_{14}$ & & 47 & 2 & 1 & 0 & \\
\hline$p$-Cymene & $\mathrm{C}_{10} \mathrm{H}_{14}$ & & 47 & 2 & 1 & 0 & \\
\hline Myrtenal & $\mathrm{C}_{10} \mathrm{H}_{14} \mathrm{O}$ & & 78 & 2 & 1 & 0 & \\
\hline Verbenone & $\mathrm{C}_{10} \mathrm{H}_{14} \mathrm{O}$ & & 85 & 2 & 2 & 0 & \\
\hline$\alpha$-Pinene & $\mathrm{C}_{10} \mathrm{H}_{16}$ & & 33 & 3 & 1 & 0 & \\
\hline$\beta$-Pinene & $\mathrm{C}_{10} \mathrm{H}_{16}$ & & 36 & 3 & 1 & 0 & \\
\hline Camphene & $\mathrm{C}_{10} \mathrm{H}_{16}$ & & 34 & 3 & 2 & 1 & \\
\hline 2-Carene & $\mathrm{C}_{10} \mathrm{H}_{16}$ & & 38 & 2 & 2 & 0 & \\
\hline 3-Carene & $\mathrm{C}_{10} \mathrm{H}_{16}$ & & 46 & 2 & 2 & 0 & \\
\hline
\end{tabular}

the literature. To develop a sustainable process and fully evaluate its benefits and drawbacks for its optimization, it is crucial to determine its impact on the environment.
Therefore, during the conducted modification of lignocellulosic fillers, passive samplers were used to collect generated VOCs and subsequently analyze them with chromatographic 
Table 2 (continued)

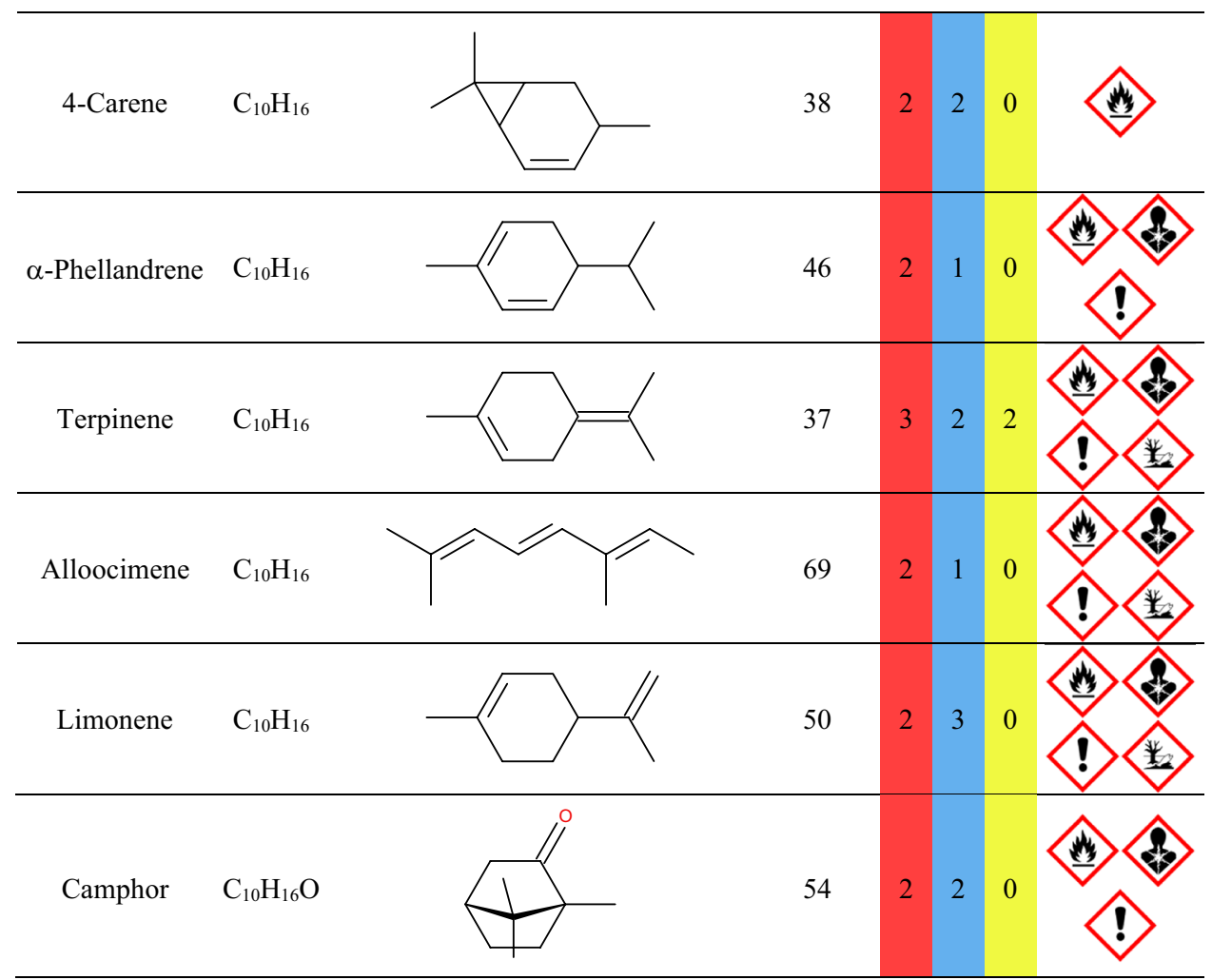

techniques. In Table 2, the main compounds generated during processing are summarized.

For all compounds, temperatures of flash point, as well as their codes and pictograms are presented according to NFPA 704: Standard System for the Identification of the Hazards of Materials for Emergency Response and Globally Harmonized System of Classification and Labelling of Chemicals, which are commonly used for classification of chemicals by the risk they pose towards human health and safety (European Parliament and the Council 2008; NFPA 2017).

NFPA 704 system is commonly known as "safety square" or "fire diamond" and is applied to quickly and easily identify the risks and select the proper procedure for handling chemicals. It is developed by National Fire Protection Association from the United States and assesses flammability, health, and instability of chemicals on a scale from 0 (minimal hazard) to 4 (severe hazard), also providing information about special hazards related to the material.

Globally Harmonized System of Classification and Labelling of Chemicals is an internationally agreed standard, which includes criteria for testing hazards and harmonized safety date sheets providing information about chemicals. It uses a combination of hazard statements and pictograms describing the physical, health and environmental properties of materials and hazards they pose to the environment.

During the modification of lignocellulosic fillers, the presence of terpenes and terpenoids was detected. The majority of them is not only considered as potentially hazardous to human health (causing skin and eye irritation or acting as allergens), but they are a serious environmental threat because of their flammability (Dev 1989). According to literature data, increasing the content of terpenes in various species of wood implicates higher fire threat (Ormeño et al. 2009). Therefore, their emission during modification of lignocellulosic materials, especially when performed on an industrial scale, should be monitored in order to prevent fire accidents.

It can be seen that almost all detected compounds are labeled as flammable according to the GHS system, and their flammability is rated as 2 or 3 on the NFPA scale, which indicates that they must be moderately heated or exposed to relatively high ambient temperature in order for ignition to occur. Rating 2 is related to flash points between 37.8 and 93. ${ }^{\circ} \mathrm{C}$ while rating 3 indicates a flash point between 22.8 and $37.8^{\circ} \mathrm{C}$ (NFPA 2017). It means that during the modification of lignocellulosic materials, serious precautions have to be taken. Depending on the actual value of ambient temperature, which is associated with the latitude and season, even the processing of cellulose materials without external heating may be considered as severe fire threat, therefore the surrounding has to be secured.

It also is very important that isocyanates were not detected during modification. The presence of a moderate amount of other chemicals, for example BTEX hydrocarbons, styrene, or chlorinated hydrocarbons was noted. However, it was ascribed to their presence in the atmosphere in 
Table 3 Compounds detected in the air during a background check of the laboratory hall

\begin{tabular}{|c|c|c|}
\hline Detected compound & Origin & References \\
\hline \multicolumn{3}{|l|}{ Hydrocarbons } \\
\hline$n$-Pentane & Polyurethane foams & Piszczyk et al. (2014) \\
\hline Hexane & Acrylic plastics, Polypropylene & Willoughby et al. (2003), Wolkoff (1988) \\
\hline Methylcyclopentane & Polypropylene & Reingruber et al. (2011) \\
\hline Methylcyclohexane & Polypropylene & Reingruber et al. (2011) \\
\hline Benzene & SBR rubber & Yu and Crump (1998) \\
\hline 2-Methylheptane & Polypropylene & Willoughby et al. (2003) \\
\hline Toluene & SBR rubber, Solvent & Yu and Crump (1998) \\
\hline Ethylbenzene & Polystyrene & Curran et al. (2016) \\
\hline Xylenes & Polyester resins, SBR rubber, Solvent & Curran et al. (2016), Yu and Crump (1998) \\
\hline Styrene & Polystyrene, Polyester resins, SBR rubber & Curran et al. (2016), Yu and Crump (1998) \\
\hline Undecane & Polyethylene, Polypropylene & Lattuati-Derieux et al. (2013) \\
\hline Dodecane & Polyethylene, Polypropylene, Natural rubber & Curran et al. (2016), Nielsen et al. (1994) \\
\hline Naphthalene & Poly(vinyl chloride) & Yu and Crump (1998) \\
\hline Tridecane & Poly(vinyl chloride), Polyethylene & Yu and Crump (1998) \\
\hline 3-Methyl tridecane & Polyester resins, Polyethylene, Polypropylene & Lattuati-Derieux et al. (2013), Yu and Crump (1998) \\
\hline Tetradecane & Polyester resins, Polyethylene, Polypropylene & Lattuati-Derieux et al. (2013), Yu and Crump (1998) \\
\hline 3-Methyl pentadecane & Polyester resins, Polyethylene, Polypropylene & Lattuati-Derieux et al. (2013), Yu and Crump (1998) \\
\hline \multicolumn{3}{|l|}{ Chlorinated hydrocarbons } \\
\hline Methylene chloride & Flame retarded polyurethane foams, Solvent & Hillier et al. (2003) \\
\hline Trichloromethane & Solvent & Stringer and Johnston (2001) \\
\hline 1,2-Dichloroethane & Solvent & Tsai et al. (2009) \\
\hline Trichloroethylene & Solvent & Stringer and Johnston (2001) \\
\hline Tetrachloroethylene & Flame retarded polyurethane foams, Solvent & Hillier et al. (2003) \\
\hline Chlorobenzene & Poly(ethylene terephthalate) & Curran et al. (2016) \\
\hline \multicolumn{3}{|l|}{ Ketones } \\
\hline Acetone & Poly(ethylene terephthalate), Solvent & Curran et al. (2016) \\
\hline 2-Heptanone & Polyethylene & Villberg and Veijanen (2001) \\
\hline \multicolumn{3}{|l|}{ Aldehydes } \\
\hline Pentanal & Natural rubber, Polyethylene & $\begin{array}{l}\text { Curran et al. (2016), Hoven et al. (2003), Villberg and Veijanen } \\
\text { (2001) }\end{array}$ \\
\hline Hexanal & Natural rubber, Polyethylene & $\begin{array}{l}\text { Curran et al. (2016), Hoven et al. (2003), Villberg and Veijanen } \\
\text { (2001) }\end{array}$ \\
\hline Heptanal & Polyethylene & Villberg and Veijanen (2001) \\
\hline Benzaldehyde & Polyester resins & Curran et al. (2016) \\
\hline \multicolumn{3}{|l|}{ Others } \\
\hline Acetic acid & Natural rubber, Polyethylene & Curran et al. (2016), Hoven et al. (2003) \\
\hline Ethyl acetate & Solvent & Riemenschneider and Bolt (2005) \\
\hline Dimethylformamide & Solvent & De Vasconcelos et al. (2001) \\
\hline Benzothiazole & Rubbers-vulcanization accelerators & Reemtsma et al. (1995) \\
\hline Diethyl phthalate & Various plastics-plasticizer & Hauser et al. (2004) \\
\hline
\end{tabular}

the laboratory during modification associated with storage and processing of various polymer materials, such as rubbers, polyurethanes or polyolefins. Detected compounds are listed in Table 3. The strongest signals were observed for toluene and tetrachloroethylene, which are used as solvent, but also associated with the major activities in the laboratory hall-manufacturing of rubbers and flame retarded polyurethane foams.

\subsection{VOCs emission from modified lignocellulosic fillers}

Figure 2 shows total VOCs emission from various Arbocel® fillers depending on IPDI content. The analysis was performed at $40{ }^{\circ} \mathrm{C}$. Clearly, the volume of emission strongly depends on the type and size of filler $(900,40$, and $8 \mathrm{~mm}$, respectively, for B400, CW630PU, and UFC100). 


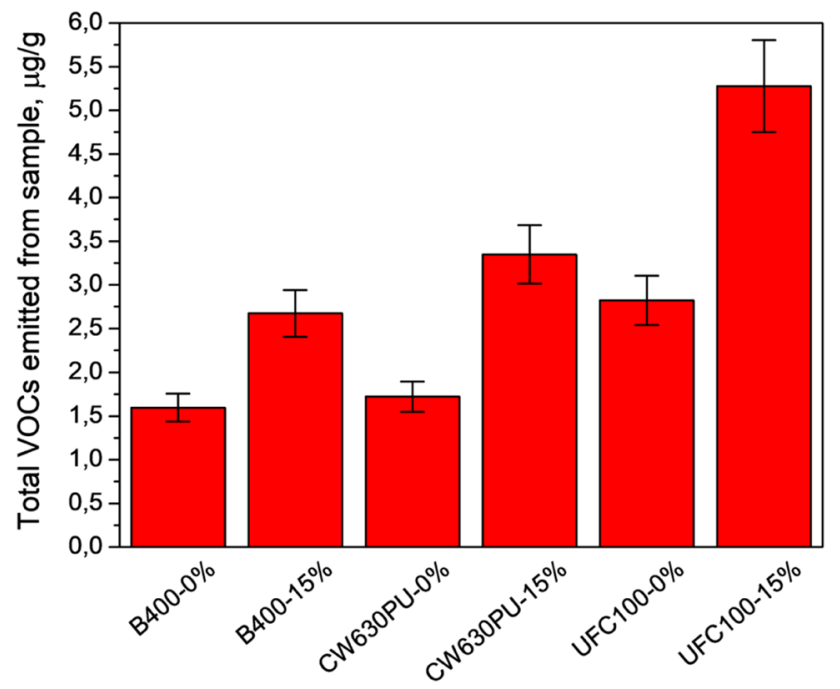

Fig. 2 Values of the TVOCs parameter measured from modified lignocellulosic fillers

Qualitatively, very similar compounds were detected for all types of fillers, so in Fig. 3, an exemplary chromatogram obtained for CW630PU modified with $15 \mathrm{wt} \%$ of IPDI is presented. Traces of limonene (retention time of $13.53 \mathrm{~min}$ ) were detected. However, the main compound emitted from modified fillers was by far IPDI (retention times of 21.65 and $21.97 \mathrm{~min}$ ), whose emission strongly depends on temperature (vapor pressure at $50{ }^{\circ} \mathrm{C}$ is more than 30 times higher than at $20{ }^{\circ} \mathrm{C}$ ). Therefore, it was detected despite its absence during modification (European Aliphatic Isocyanates Producers Association 2013). It accounted for around 41, 60, and $63 \%$ of the area below the peaks present on the chromatograms obtained for B400, CW630PU, and UFC100 fillers, respectively. Moreover, the presence of a moderate amount of other chemicals, for example BTEX hydrocarbons or solvents (e.g., acetone at $4.58 \mathrm{~min}$, butanone at $5.64 \mathrm{~min}$, or butanone oxime at $8.59 \mathrm{~min}$ ) was noted. It was ascribed to their presence in the atmosphere in the laboratory during modification associated with the processing of various polymer materials.

\subsection{Particle size distribution}

In Fig. 4, the plots are showing the particle size distribution of modified fillers as a function of IPDI content. The analysis was performed for samples without IPDI and for those containing 1,5 , and $15 \mathrm{wt} \%$ of modifier. In the case of B400 fillers, the determination of particle size for the highest content of IPDI was impossible because of the very strong agglomeration of fillers after modification. Samples named $0 \%$ on the graphs were also mechanically treated in a Brabender mixer. Therefore, their average particle size differs from the values provided by the producer (see Table 1). It can be noted that the addition of isocyanate increased the average particle size, which is associated with the generation of urethane bonds, linking separate fillers. Such effect was expected due to the high reactivity of isocyanate functional groups of IPDI and the multiplicity of hydroxyl groups on the surface of lignocellulosic fillers. Nevertheless, in the case of CW630PU and UFC100 fillers, modification with an IPDI content not exceeding $5 \mathrm{wt} \%$ did not show a very significant impact on the particle size distribution. For B400 samples, the effect was more noticeable because the average particle size was increased from 278 to $344 \mu \mathrm{m}$. Nevertheless, no significant agglomeration was noted. Such an effect should be considered as very beneficial for further manufacturing of polymer composites because the size of filler has a noticeable influence on their performance.

\subsection{Microscopic analysis of modified fillers}

Figure 5 shows SEM images of the investigated fillers before and after the modification with IPDI. It can be clearly seen that the performed treatment resulted in the changes of the
Fig. 3 Exemplary chromatogram obtained during the $\mu \mathrm{CTE}-\mathrm{TD}-\mathrm{GC}-\mathrm{MS}$ analysis of selected CW630PU fillers modified with $15 \mathrm{wt} \%$ of IPDI

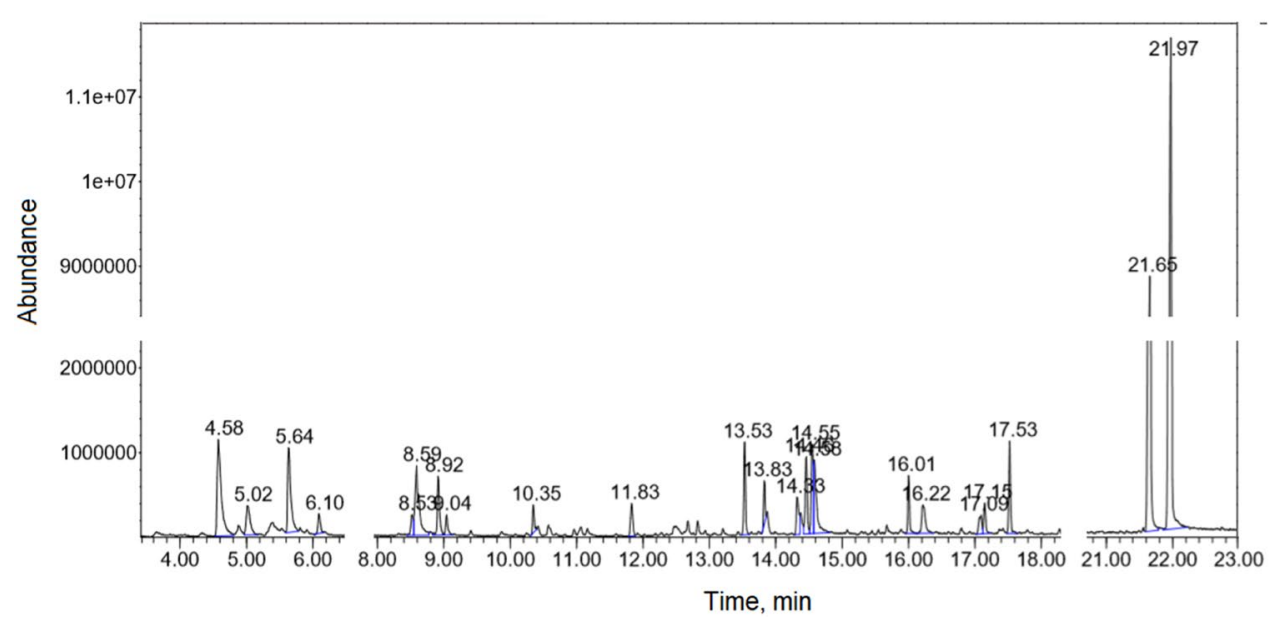


fillers' surface. After treatment, the surface became rougher, which is indicated by the circles in the SEM images. Such an effect can be associated with the chemical reactions occurring between diisocyanate modifier and hydroxyl groups present on the surface of fillers. As a result, diisocyanate was deposited on the surface and might also cause sticking of the smaller particles of cellulosic fillers. Nevertheless, microscopic analysis confirmed a rather low agglomeration effect, as indicated by the results of particle size analysis. Nevertheless, some changes in the aspect ratio of fillers may be noted, especially in case of CW630PU and UFC100 fillers. For relatively long fibers of B400 filler, the rise of particle size was rather related to the entanglements of fibers. In case of other, less fibrous, fillers, the drop of aspect ratio, especially for $15 \mathrm{wt} \%$ content of IPDI, was related to sticking of the particles to each other. It can be seen in Fig. $5 f$ and i. Such an effect only slightly affected the average diameter, but particles changed their form from flake-like to more spherical shape.

\subsection{Chemical structure}

Figure 6 shows the spectra of three types of fillers modified with $15 \mathrm{wt} \%$ of IPDI. It can be seen that all spectra show an appearance typical for lignocellulosic materials. Signals between 3340 and $3355 \mathrm{~cm}^{-1}$ are characteristic for stretching vibrations of hydroxyl groups present on the surface of fillers. They all show relatively high intensity after modification, which is related to their overlapping with signals associated with stretching vibrations of $\mathrm{N}-\mathrm{H}$ bonds, which are generated during the modification with isocyanate. In the range of $2880-2960 \mathrm{~cm}^{-1}$, peaks characteristic for symmetric and asymmetric stretching vibrations of $\mathrm{C}-\mathrm{H}$ bonds can be noticed. Broad signals between 2250 and $2340 \mathrm{~cm}^{-1}$ were ascribed to the asymmetric stretching vibrations of free isocyanate groups, which was related to the performed modifications. Prominent peaks around $1740 \mathrm{~cm}^{-1}$ were attributed to the vibrations of carbonyl group present in urethane linkage between filler and IPDI. The presence of these peaks confirms the successful modification of lignocellulosic fillers. Other very noticeable peaks were observed in the range of $1010-1050 \mathrm{~cm}^{-1}$ and were characteristic for the vibrations of $\mathrm{C}-\mathrm{O}$ bonds present in the structure of cellulose. Multiple signals noted in the range of $1100-1450 \mathrm{~cm}^{-1}$ were associated with the bending vibrations of $\mathrm{C}-\mathrm{H}$ bonds, stretching of various $\mathrm{C}-\mathrm{O}-\mathrm{C}$ groups, and $\mathrm{C}-\mathrm{C}$ bonds. The presence of a large amount of small signals in this range is typical for lignocellulosic fillers (Barczewski et al. 2018; Matykiewicz et al. 2019).

Figure 7 presents spectra of UFC100 fillers modified with varying amounts of isophorone diisocyanate. It can be seen that an increase in the modifier content results in a noticeable rise of particular signals associated with the presence of urethane linkages between fillers and isocyanate. The most significant impact of modifier was noted for signals around 2250-2340 and $1740 \mathrm{~cm}^{-1}$, related to
Fig. 4 Particle size distribution of modified lignocellulosic Arbocel ${ }^{\circledR}$ fillers: a B400, b CW630PU and $\mathbf{c}$ UFC100
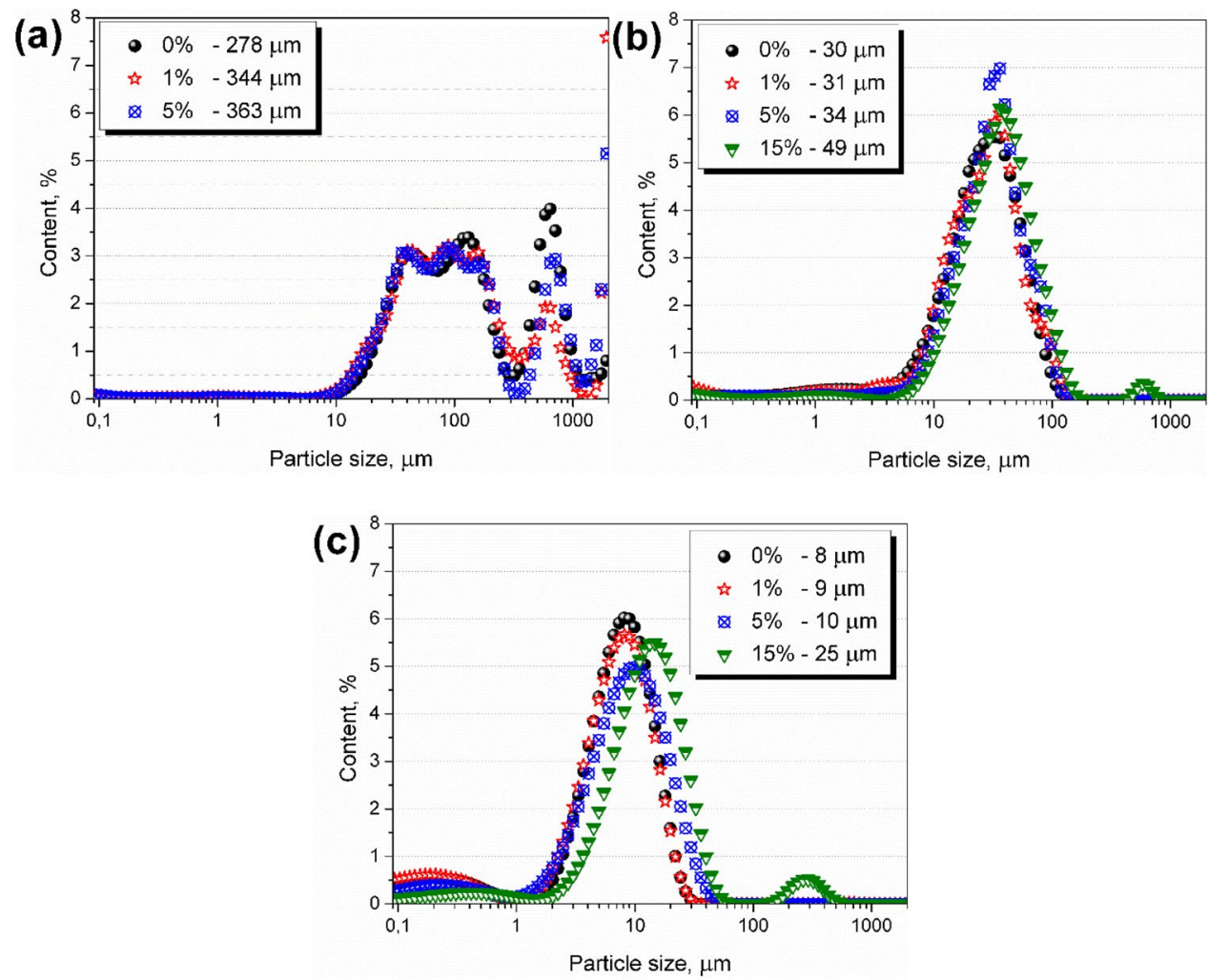

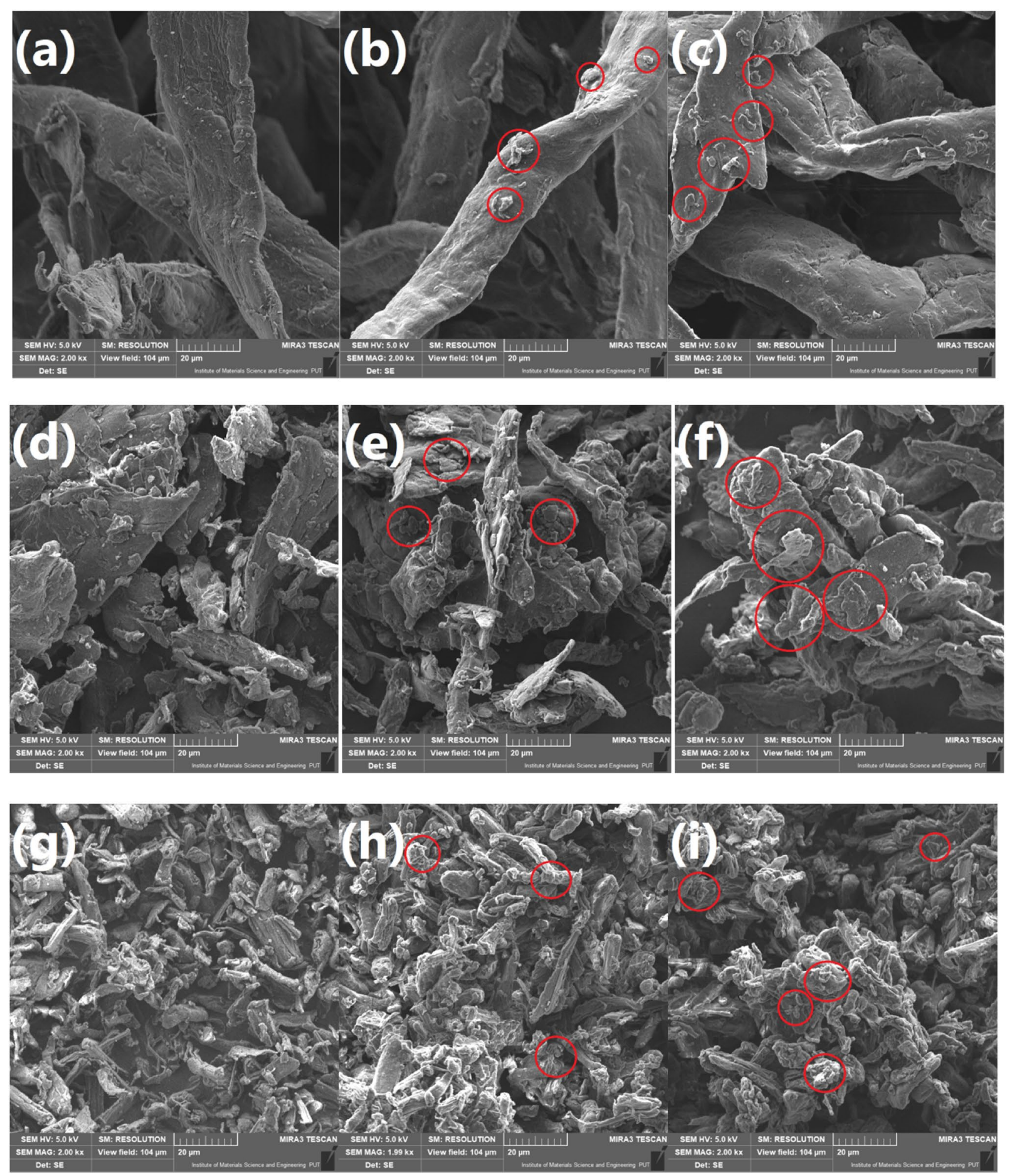

Fig. 5 SEM images of a-c B400, d-f CW630PU, and $\mathbf{g}-\mathbf{i}$ UFC100 fillers: a, d, $\mathbf{g}$ unmodified, and modified with $\mathbf{b}, \mathbf{e}, \mathbf{h} 5$ and $\mathbf{c}, \mathbf{f}, \mathbf{i} 15$ wt $\%$ of IPDI

the unbonded isocyanate groups and $\mathrm{C}=\mathrm{O}$ stretching in urethane groups. Similar effects were observed by other researchers for the isocyanate modification of cellulose fillers (Botaro and Gandini 1998; Siqueira et al. 2010). Moreover, a slight rise in the intensity and changes in the shape of the broad signal around $3350 \mathrm{~cm}^{-1}$ were noted, 


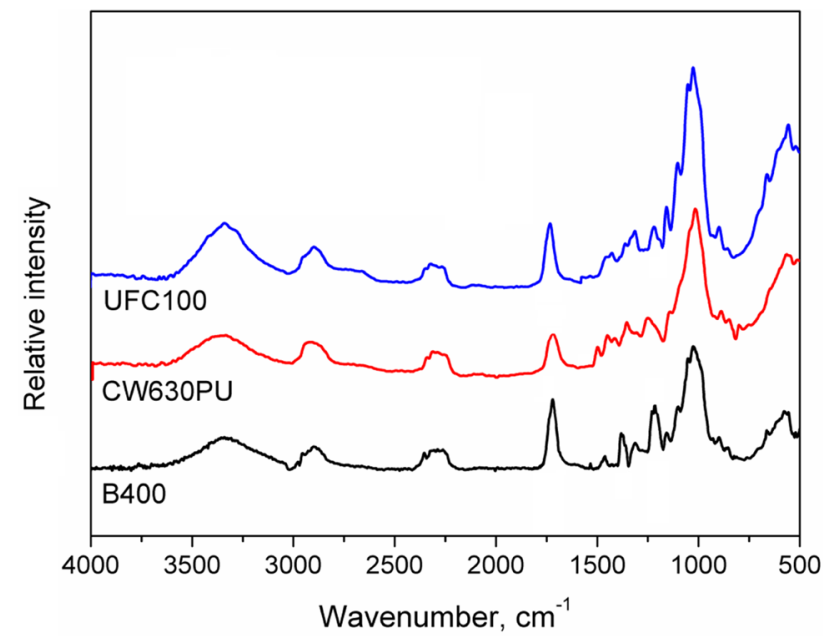

Fig. 6 FTIR spectra of lignocellulosic fillers modified with 15 wt $\%$ of IPDI

which was associated with the reaction between hydroxyls present on the surface of fillers and isocyanate groups of the modifier. As mentioned above, it resulted in the generation of urethane groups, which also contain $\mathrm{N}-\mathrm{H}$ bonds. Signals characteristic for them are practically overlapping with those of hydroxyl groups, hence only slight changes were noted (Gao et al. 2005).

\subsection{Color assessment}

In Table 4, the color parameters of the prepared samples determined during spectrophotometric analysis are presented. The color of materials was evaluated using CIELab

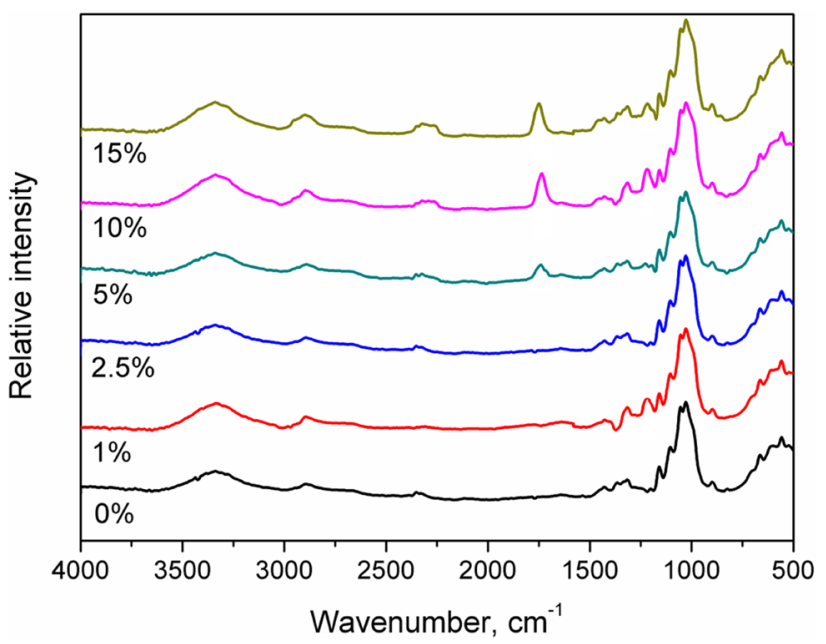

Fig. 7 FTIR spectra of UFC100 fillers modified with varying content of IPDI

color space and converted to popular Adobe RGB space. Moreover, values of total color difference parameter $\left(\Delta \mathrm{E}^{*}\right)$ associated with performed modifications, related to unmodified, reference samples, are presented, as well as colors of obtained materials.

It can be seen that applied modifications of lignocellulosic fillers with IPDI caused some changes in $\mathrm{L}^{*}$ and $b^{*}$ parameters. The decrease in the lightness of fillers was associated with the increase in their average particle size. Such a phenomenon is commonly known and widely described in the literature by various researchers (Ahmed et al. 2014, 2015, 2016). Rise of b* parameter is related to
Table 4 Color properties of modified lignocellulosic fillers

\begin{tabular}{|c|c|c|c|c|c|c|c|c|c|}
\hline \multirow{2}{*}{ Filler type } & \multirow{2}{*}{$\begin{array}{c}\text { IPDI } \\
\text { content, } \\
\mathrm{wt}^{0} \%\end{array}$} & \multicolumn{8}{|c|}{ Color parameters } \\
\hline & & $\mathrm{L}^{*}$ & $a^{*}$ & $b^{*}$ & $\Delta \mathrm{E}^{*}$ & $\mathrm{R}$ & G & B & Color \\
\hline \multirow{6}{*}{ B400 } & 0.0 & 93.55 & -0.62 & 4.45 & - & 237.8 & 235.9 & 227.5 & \\
\hline & 1.0 & 93.14 & -0.63 & 4.63 & 0.45 & 236.7 & 234.7 & 226.0 & \\
\hline & 2.5 & 93.46 & -0.59 & 4.52 & 0.12 & 237.6 & 235.6 & 227.1 & \\
\hline & 5.0 & 92.65 & -0.62 & 4.86 & 0.99 & 235.4 & 233.2 & 224.1 & \\
\hline & 10.0 & 91.56 & -0.63 & 5.47 & 2.24 & 232.6 & 230.0 & 219.8 & \\
\hline & 15.0 & 91.63 & -0.63 & 5.67 & 2.27 & 232.9 & 230.2 & 219.7 & \\
\hline \multirow{6}{*}{ CW630PU } & 0.0 & 85.38 & 2.01 & 15.30 & - & 223.2 & 209.9 & 184.4 & \\
\hline & 1.0 & 85.17 & 2.04 & 15.17 & 0.25 & 222.5 & 209.3 & 184.1 & \\
\hline & 2.5 & 84.32 & 2.25 & 15.88 & 1.23 & 220.7 & 206.7 & 180.5 & \\
\hline & 5.0 & 83.84 & 2.31 & 15.93 & 1.69 & 219.4 & 205.3 & 179.1 & \\
\hline & 10.0 & 82.31 & 2.72 & 17.22 & 3.69 & 216.0 & 200.7 & 172.6 & \\
\hline & 15.0 & 81.28 & 3.05 & 18.24 & 5.15 & 213.9 & 197.5 & 168.0 & \\
\hline \multirow{6}{*}{ UFC100 } & 0.0 & 96.46 & -0.04 & 1.91 & - & 245.6 & 244.3 & 240.8 & \\
\hline & 1.0 & 96.41 & -0.05 & 1.87 & 0.06 & 245.4 & 244.2 & 240.7 & \\
\hline & 2.5 & 96.31 & -0.04 & 1.95 & 0.16 & 245.2 & 243.9 & 240.3 & \\
\hline & 5.0 & 96.28 & -0.05 & 1.97 & 0.19 & 245.1 & 243.8 & 240.2 & \\
\hline & 10.0 & 96.12 & -0.01 & 2.54 & 0.72 & 245.0 & 243.3 & 238.6 & \\
\hline & 15.0 & 96.40 & -0.03 & 2.32 & 0.41 & 245.7 & 244.1 & 239.9 & \\
\hline
\end{tabular}



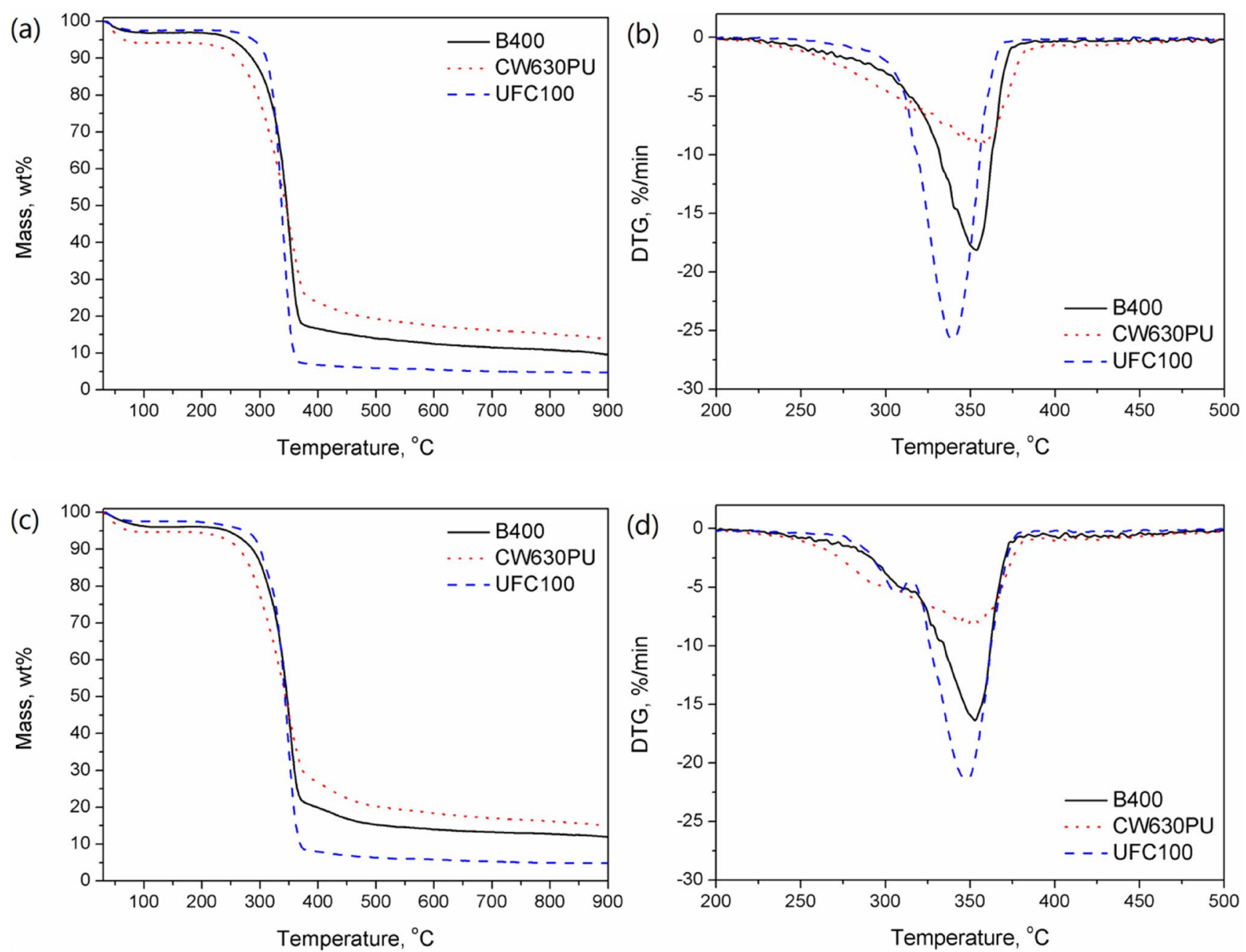

Fig. 8 Results of thermogravimetric analysis for fillers modified with $\mathbf{a}, \mathbf{b} 1 \mathrm{wt} \%$ and $\mathbf{c}, \mathbf{d} 15 \mathrm{wt} \%$ of IPDI

Table 5 Moisture content of modified lignocellulosic fillers

\begin{tabular}{|c|c|c|c|c|c|c|c|c|}
\hline Filler type & $\begin{array}{l}\text { IPDI content, } \\
\text { wt } \%\end{array}$ & $\begin{array}{l}\text { Moisture con- } \\
\text { tent, wt } \%\end{array}$ & Filler type & $\begin{array}{l}\text { IPDI content, } \\
\text { wt } \%\end{array}$ & $\begin{array}{l}\text { Moisture con- } \\
\text { tent, wt } \%\end{array}$ & Filler type & $\begin{array}{l}\text { IPDI content, } \\
\text { wt } \%\end{array}$ & $\begin{array}{l}\text { Moisture } \\
\text { content, } \\
\text { wt } \%\end{array}$ \\
\hline \multirow[t]{6}{*}{ B400 } & 0.0 & 6.28 & \multirow[t]{6}{*}{ CW630PU } & 0.0 & 7.10 & \multirow[t]{6}{*}{ UFC100 } & 0.0 & 4.87 \\
\hline & 1.0 & 6.18 & & 1.0 & 6.98 & & 1.0 & 4.49 \\
\hline & 2.5 & 5.94 & & 2.5 & 6.76 & & 2.5 & 4.53 \\
\hline & 5.0 & 5.46 & & 5.0 & 6.45 & & 5.0 & 4.36 \\
\hline & 10.0 & 5.33 & & 10.0 & 6.44 & & 10.0 & 4.31 \\
\hline & 15.0 & 4.82 & & 15.0 & 6.28 & & 15.0 & 4.18 \\
\hline
\end{tabular}

the yellowing of cellulose, as a result of mechanical and chemical treatment (Ahn et al. 2019).

However, overall, it can be seen that the performed modifications of fillers did not cause significant differences in their color, which was expressed by relatively low values of $\Delta \mathrm{E}^{*}$ parameter. Only for B400 and CW630PU fillers modified with higher contents of IPDI, the values were exceeding 2.0, indicating medium color variations, recognizable by the inexperienced observer, while distinct and significant color variations were noted only for CW630PU fillers (Bociąga and Trzaskalska 2016). Such information is very important for the potential industrial 


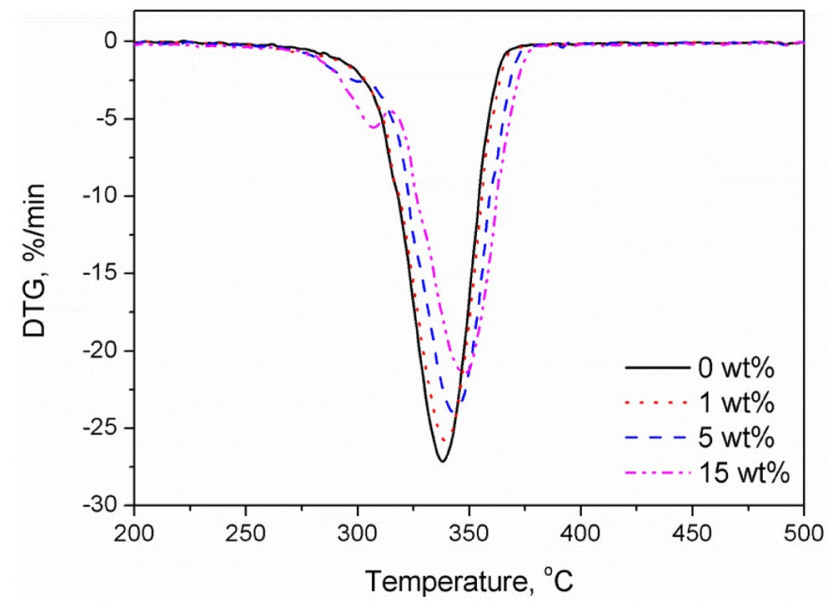

Fig. 9 Differential thermogravimetric curves depending on the IPDI content for modified UFC100 filler

application of investigated modification process. The appearance of wood polymer composites is often crucial for the final recipients of the products, and it is significantly affected by the appearance of introduced fillers,

\subsection{Thermal stability}

Figure 8 presents the results of the thermogravimetric analysis of modified lignocellulosic fillers. It can be seen that thermal stability strongly depends on the type of filler. Obviously, the first step of decomposition, below $100^{\circ} \mathrm{C}$, is related to the moisture content of particular samples, whose values are presented in Table 5. Its varying values can be associated with differences in the chemical composition, as well as particle size, hence surface area of fillers. All those factors are significantly affecting the water absorption of lignocellulosic fillers. A drop in moisture content with increasing amount of applied modifier is associated with changes in the chemical structure of the surface and reduced polarity compared to unmodified samples.

Generally, it can be seen that B400 and UFC100 samples show quite similar behavior, while more significant differences are observed for CW630PU filler. Such effect is associated with the cellulose content, which for B400 and UFC100 fillers is significantly higher than for CW630PU. All lignocellulosic fillers show quite a similar course of decomposition, and differences are associated mainly with moisture content. CW630PU fillers, despite the lowest thermal stability (highest moisture content), show the highest content of residue after analysis. Such an effect can be attributed to the lignin content, which decomposes quite slowly and produces a high yield of char (Brebu and Vasile 2010). Moreover, differential thermogravimetric (DTG) curves for lignin are rather flat, with no sharp peaks comparing to cellulose and hemicellulose, which can be confirmed by the presented results (Yang et al. 2006).

With the increase in IPDI content, slight changes in thermal decomposition are observed (Figs. 8 and 9). Especially in the case of the UFC100 sample, an additional peak is noted at DTG curves around $305^{\circ} \mathrm{C}$. Such effect is associated with thermal degradation of urethane bonds generated as a result of isocyanate groups of modifiers with hydroxyls present on the surface of lignocellulosic fillers (Hejna et al. 2017). Moreover, char residue generated during degradation of urethane bonds, containing noticeable amounts of nitrogen, may partly act as an inhibitor of further degradation. Hence, peaks on DTG curves are slightly shifted towards higher temperatures.

\section{Conclusion}

Structure and properties of three types of lignocellulosic fillers modified with isophorone diisocyanate were investigated to determine its potential for application as a dispersed phase for wood polymer composites. Fillers were modified with different contents of IPDI (from 1 to $15 \mathrm{wt} \%$ ) using the internal mixer. The emission of volatile organic compounds during modification was analyzed. The main detected compounds were terpenes and terpenoids, which, despite their lower harmfulness compared to IPDI, show irritating and allergic character. Moreover, they are characterized by relatively low values of flash point, even below $40{ }^{\circ} \mathrm{C}$. Therefore, precautions need to be taken during modifications of lignocellulosic fillers.

At a slightly elevated temperature of $40{ }^{\circ} \mathrm{C}$, IPDI was detected among VOCs emitted from modified fillers (vapor pressure of IPDI significantly increases with temperature). It suggests that part of the applied modifier was only deposited on the surface of the filler, which was confirmed by FTIR analysis, indicating the presence of free isocyanate groups in the structure of modified fillers. On the other hand, the generation of urethane bonds on the surface of fillers was noted, confirming successful modification.

Regarding particle size, IPDI-treatment increased this parameter. For B400 filler, the addition of 1 and $5 \mathrm{wt} \%$ of modifier caused an increase from $278 \mu \mathrm{m}$ to 344 and $363 \mu \mathrm{m}$, respectively. For other types of fillers, such contents of IPDI did not cause significant effects. Increasing the amount of modifier to $15 \mathrm{wt} \%$ resulted in the rise of particle size from 30 to $49 \mu \mathrm{m}$ and from 8 to $25 \mu \mathrm{m}$, for CW630PU and UFC100 fillers, respectively. Such an effect was associated with slight agglomeration of particles. For the color of the lignocellulosic fillers, the effect of modification also was not very significant. Color differences, which could be considered as recognizable by the inexperienced observer were noted only for B400 and CW630PU fillers modified 
with 10 or 15 wt $\%$ of IPDI. Moreover, for CW630PU filler modified with $15 \mathrm{wt} \%$, color changes could be categorized as distinct and significant.

We believe that the presented paper provided valuable insights into the issue of isocyanate modifications of lignocellulosic fillers and what is important, in contrast to the majority of the papers, not only focused on properties of modified fillers, but also their impact on human health and the surrounding environment.

Acknowledgements This work was supported by the National Science Centre (NCN, Poland) in the frame of SONATINA 2 project 2018/28/C/ST8/00187 - Structure and properties of lignocellulosic fillers modified in situ during reactive extrusion. The Authors would also like to thank dr. Adam Piasecki from the Institute of Materials Engineering of Poznan University of Technology for the valuable help with the investigation of the microscopic structure of modified fillers.

\section{Compliance with ethical standards}

Conflict of interest All author(s) declare that they have no conflict no interest.

Open Access This article is licensed under a Creative Commons Attribution 4.0 International License, which permits use, sharing, adaptation, distribution and reproduction in any medium or format, as long as you give appropriate credit to the original author(s) and the source, provide a link to the Creative Commons licence, and indicate if changes were made. The images or other third party material in this article are included in the article's Creative Commons licence, unless indicated otherwise in a credit line to the material. If material is not included in the article's Creative Commons licence and your intended use is not permitted by statutory regulation or exceeds the permitted use, you will need to obtain permission directly from the copyright holder. To view a copy of this licence, visit http://creativecommons.org/licenses/by/4.0/.

\section{References}

Ahmed J, Al-Foudari M, Al-Salman F, Almusallam AS (2014) Effect of particle size and temperature on rheological, thermal, and structural properties of pumpkin flour dispersion. J Food Eng 124:43-53. https://doi.org/10.1016/j.jfoodeng.2013.09.030

Ahmed J, Al-Jassar S, Thomas L (2015) A comparison in rheological, thermal, and structural properties between Indian Basmati and Egyptian Giza rice flour dispersions as influenced by particle size. Food Hydrocolloid 48:72-83. https://doi.org/10.1016/j.foodh yd.2015.02.012

Ahmed J, Al-Attar H, Arfat YA (2016) Effect of particle size on compositional, functional, pasting and rheological properties of commercial water chestnut flour. Food Hydrocolloid 52:888-895. https://doi.org/10.1016/j.foodhyd.2015.08.028

Ahn K, Zaccaron S, Zwirchmayr NS, Hettegger H, Hofinger A, Bacher M, Henniges U, Hosoya T, Potthast A, Rosenau T (2019) Yellowing and brightness reversion of celluloses: $\mathrm{CO}$ or $\mathrm{COOH}$, who is the culprit? Cellulose 26:429-444. https://doi.org/10.1007/s 1057 0-018-2200-x

Ashori A, Nourbakhsh A (2009) Polypropylene cellulose-based composites: the effect of bagasse reinforcement and polybutadiene isocyanate treatment on the mechanical properties. J Appl Polym Sci 111:1684-1689. https://doi.org/10.1002/app.29189

Barczewski M, Szostak M, Nowak D, Piasecki A (2018) Effect of wood flour addition and modification of its surface on the properties of rotationally molded polypropylene composites. Polimery 63(1112):772-784. https://doi.org/10.14314/polimery.2018.11.5

Błędzki AK, Mamun AA, Lucka-Gabor M, Gutowski VS (2008) The effects of acetylation on properties of flax fibre and its polypropylene composites. Express Polym Lett 2:413-422. https://doi. org/10.3144/expresspolymlett.2008.50

Bociaga E, Trzaskalska M (2016) Influence of polymer processing parameters and coloring agents on gloss and color of acrylonitrilebutadiene-styrene terpolymer moldings. Polimery 61:544-550. https://doi.org/10.14314/polimery.2016.544

Botaro VR, Gandini A (1998) Chemical modification of the surface of cellulosic fibres. 2. Introduction of alkenyl moieties via condensation reactions involving isocyanate functions. Cellulose 5(2):65-78. https://doi.org/10.1023/a:1009216729686

Brebu M, Vasile C (2010) Thermal degradation of lignin-a review. Cell Chem Technol 44(9):353-363

Colom X, Carrasco F, Pages P, Cañavate J (2003) Effects of different treatments on the interface of HDPE/lignocellulosic fiber composites. Compos Sci Technol 63:161-169. https://doi.org/10.1016/ S0266-3538(02)00248-8

Curran K, Underhill M, Gibson LT, Strlic M (2016) The development of a SPME-GC/MS method for the analysis of VOC emissions from historic plastic and rubber materials. Microchem J 124:909918. https://doi.org/10.1016/j.microc.2015.08.027

Dányádi L, Móczó J, Pukánszky B (2010) Effect of various surface modifications of wood flour on the properties of PP/wood composites. Compos Part A Appl S 41:199-206. https://doi.org/10.1016/j. compositesa.2009.10.008

De Vasconcelos C, Martins R, Ferreira M, Pereira M, Fonseca J (2001) Rheology of polyurethane solutions with different solvents. Polym Int 51(1):69-74. https://doi.org/10.1002/pi.800

Dev S (1989) Terpenoids. In: Wimmer R (eds) Springer Series in Wood Science. Springer, New York, pp 691-807. https://doi. org/10.1007/978-3-642-74075-6_19

Doustmohammadi N, Babazadeh R (2019) Design of closed loop supply chain of wood plastic composite (WPC) industry. J Environ Inform. https://doi.org/10.3808/jei.201900419

European aliphatic isocyanates producers association (2013) Properties, Hazards and safety information for IPDI. https://www.alipa .org/uploads/IPDI.pdf. Accessed 22 Nov 2019

European Parliament and the Council (2008) Regulation (EC) No $1272 / 2008$ of the European Parliament and of the Council of 16 December 2008 on classification, labelling and packaging of substances and mixtures, amending and repealing Directives 67/548/EEC and 1999/45/EC, and amending Regulation (EC) No 1907/2006. https://eur-lex.europa.eu/LexUriServ/LexUriServ.do? uri=OJ:L:2008:353:0001:1355:EN:PDF. Accessed 22 Nov 2019

Gao ZH, Gu JY, Wang X, Li ZG, Bai XD (2005) FTIR and XPS study of the reaction of phenyl isocyanate and cellulose with different moisture contents. Pigm Resin Technol 34(5):282-289. https:// doi.org/10.1108/03699420510620300

Geng Y, Li K, Simonsen J (2005) A combination of poly(diphenylmethane diisocyanate) and stearic anhydride as a novel compatibilizer for wood-polyethylene composites. J Adhes Sci Technol 19:987-1001. https://doi.org/10.1163/1568561054 951013

Girouard NM, Xu S, Schueneman GT, Shofner ML, Meredith JC (2016) Site-Selective modification of cellulose nanocrystals with isophorone diisocyanate and formation of polyurethane-CNC composites. ACS Appl Mater Inter 8(2):1458-1467. https://doi. org/10.1021/acsami.5b10723 
Gómez-Fernández S, Ugarte L, Calvo-Correas T, Pena-Rodriguez C, Corcuera MA, Eceiza A (2017) Properties of flexible polyurethane foams containing isocyanate functionalized kraft lignin. Ind Crop Prod 100:51-64. https://doi.org/10.1016/j.indcrop.2017.02.005

Hauser R, Duty S, Godfrey-Bailey L, Calafat AM (2004) Medications as a source of human exposure to phthalates. Environ Health Persp 112(6):751-753. https://doi.org/10.1289/ehp.6804

Hejna A, Kosmela P, Kirpluks M, Cabulis U, Klein M, Haponiuk J, Piszczyk $Ł$ (2017) Structure, mechanical, thermal and fire behavior assessments of environmentally friendly crude glycerol-based rigid polyisocyanurate foams. J Polym Environ 26(5):1854-1868. https://doi.org/10.1007/s10924-017-1086-2

Hillier K, Schupp T, Carney I (2003) An investigation into VOC emissions from polyurethane flexible foam mattresses. Cell Polym 22(4):237-259. https://doi.org/10.1177/026248930302200402

Hoven VP, Rattanakaran K, Tanaka Y (2003) Determination of chemical components that cause mal-odor from natural rubber. Rubber Chem Technol 76(5):1128-1144. https://doi.org/10.5254/1.35477 92

International Commission on Illumination (1978) Recommendations on uniform color spaces, color-difference equations, psychometric color terms, Bureau central de la C.I.E., Paris, France

Joseph K, Thomas S, Pavithran C (1995) Effect of ageing on the physical and mechanical properties of sisal-fiber-reinforced polyethylene composites. Compos Sci Technol 53(1):99-110. https://doi.org/10.1016/0266-3538(94)00074-3

Joseph K, Thomas S, Pavithran C (1996) Effect of chemical treatment on the tensile properties of short sisal fibre-reinforced polyethylene composites. Polymer 37(23):5139-5149. https:// doi.org/10.1016/0032-3861(96)00144-9

Keskisaari A, Kärki T (2016) Raw material potential of recyclable materials for fiber composites: a review study. J Mater Cycles Waste 19(3):1136-1143. https://doi.org/10.1007/s1016 3-016-0511-2

Król S, Zabiegała B, Namieśnik J (2012) Measurement of benzene concentration in urban air using passive sampling. Anal Bioanal Chem 403:1067-1082. https://doi.org/10.1007/s0021 6-011-5578-y

Lattuati-Derieux A, Egasse C, Thao-Heu S, Balcar N, Barabant G, Lavédrine B (2013) What do plastics emit? HS-SPME-GC/MS analyses of new standard plastics and plastic objects in museum collections. J Cult Herit 14(3):238-247. https://doi.org/10.1016/j. culher.2012.06.005

Maldas D, Kokta BV, Raj RG, Daneault C (1988) Improvement of the mechanical properties of sawdust wood fibre-polystyrene composites by chemical treatment. Polymer 29(7):1255-1265. https ://doi.org/10.1016/0032-3861(88)90053-5

Maldas D, Kokta BV, Daneault C (1989) Thermoplastic composties of polystyrene: effect of different wood species on mechanical properties. J Appl Polym Sci 38(3):413-439. https://doi.org/10.1002/ app.1989.070380303

Marć M, Zabiegała B (2017) An investigation of selected monoaromatic hydrocarbons released from the surface of polystyrene lids used in coffee-to-go cups. Microchem J 133:496-505. https://doi. org/10.1016/j.microc.2017.04.015

Marć M, Namieśnik J, Zabiegała B (2014a) Small-scale passive emission chamber for screening studies on monoterpene emission flux from the surface of wood-based indoor elements. Sci Total Environ 481:35-46. https://doi.org/10.1016/j.scitotenv.2014.02.021

Marć M, Zabiegała B, Namieśnik J (2014b) Application of passive sampling technique in monitoring research on quality of atmospheric air in the area of Tczew, Poland. Int J Environ Anal Chem 94:151-167. https://doi.org/10.1080/03067319.2013.791979

Marć M, Namieśnik J, Zabiegała B (2017) The miniaturised emission chamber system and home-made passive flux sampler studies of monoaromatic hydrocarbons emissions from selected commercially-available floor coverings. Build Environ 123:1-13. https://doi.org/10.1016/j.buildenv.2017.06.035

Matykiewicz D, Barczewski M, Mysiukiewicz O, Skórczewska K (2019) Comparison of various chemical treatments efficiency in relation to the properties of flax, hemp fibers and cotton trichomes. J Nat Fibers. https://doi.org/10.1080/15440478.2019.1645792

Morelli CL, Belgacem MN, Branciforti MC, Bretas RES, Crisci A, Bras J (2015) Supramolecular aromatic interactions to enhance biodegradable film properties through incorporation of functionalized cellulose nanocrystals. Compos Part A Appl S 83:80-88. https://doi.org/10.1016/j.compositesa.2015.10.038

Musk AW, Peters JM, Wegman DH (1988) Isocyanates and respiratory disease: current status. Am J Ind Med 13:331-349. https://doi. org/10.1002/ajim.4700130304

Nair KCM, Thomas S (2003) Effect of interface modification on the mechanical properties of polystyrene-sisal fiber composites. Polym Compos 24(3):332-343. https://doi.org/10.1002/pc.10033

NFPA (2017) NFPA 704: standard system for the identification of the hazards of materials for emergency response. https://www.nfpa. org/codes-and-standards/all-codes-and-standards/list-of-codes -and-standards/detail?code $=704$. Accessed 22 Nov 2019

Nielsen PA, Jensen LK, Eng K, Bastholm P, Hugod C, Husemoen T, Molhave L, Wolkoff P (1994) Health-related evaluation of building products based on climate chamber tests. Indoor Air 4(3):146153. https://doi.org/10.1111/j.1600-0668.1994.t01-1-00003.x

Ormeño E, Céspedes B, Sánchez IA, Velasco-García A, Moreno JM, Fernandez C, Baldy V (2009) The relationship between terpenes and flammability of leaf litter. Forest Ecol Manag 257(2):471482. https://doi.org/10.1016/j.foreco.2008.09.019

Paul A, Joseph K, Thomas S (1997) Effect of surface treatments on the electrical properties of low-density polyethylene composites reinforced with short sisal fibers. Compos Sci Technol 57(1):67-79. https://doi.org/10.1016/s0266-3538(96)00109-1

Piszczyk Ł, Hejna A, Formela K, Danowska M, Strankowski M (2014) Morphology, mechanical and thermal properties of fexible polyurethane foams modified with layered aluminosilicates. Polimery 59(11-12):783-791. https://doi.org/10.14314/polimery.2014.783

Plaisance H, Leonardis T, Gerboles M (2008) Assessment of uncertainty of benzene measurements by Radiello diffusive sampler. Atmos Environ 42:2555-2568. https://doi.org/10.1016/j.atmos env.2007.12.009

Quitadamo A, Massardier V, Valente M (2019) Eco-friendly approach and potential biodegradable polymer matrix for WPC composite materials in outdoor application. Int J Polym Sci 2019:3894370. https://doi.org/10.1155/2019/3894370

Raj RG, Kokta BV, Maldas D, Daneault C (1989) Use of wood fibers in thermoplastics. VII. The effect of coupling agents in polyethylene-wood fiber composites. J Appl Polym Sci 37(4):1089-1103. https://doi.org/10.1002/app.1989.070370420

Raj RG, Kokta BV, Daneault C (1990) The use of Isocyanate as a Bonding Agent to Improve the Mechanical Properties of PolyethyleneWood Fiber Composites. Int J Polym Mater Po 14(3-4):223-234. https://doi.org/10.1080/00914039008031515

Reemtsma T, Fiehn O, Kalnowski G, Jekel M (1995) Microbial transformations and biological effects of fungicide-derived benzothiazoles determined in industrial wastewater. Environ Sci Technol 29(2):478-485. https://doi.org/10.1021/es00002a025

Reingruber E, Reussner J, Sauer C, Standler A, Buchberger W (2011) Studies on the emission behavior of polypropylene by gas chromatography/mass spectrometry with static headspace or thermodesorption. J Chromatogr A 1218(21):3326-3331. https://doi. org/10.1016/j.chroma.2010.11.021

Riemenschneider W, Bolt HM (2005) Esters, organic. In: Ullmann's encyclopedia of industrial chemistry. Wiley-VCH, Weinheim 
Siqueira G, Bras J, Dufresne A (2010) New process of chemical grafting of cellulose nanoparticles with a long chain isocyanate. Langmuir 26(1):402-411. https://doi.org/10.1021/la9028595

Stringer R, Johnston P (2001) Chlorine and the environment, an overview of the chlorine industry. Springer, New York

Tsai CJ, Chen ML, Chang KF, Chang FK, Mao IF (2009) The pollution characteristics of odor, volatile organochlorinated compounds and polycyclic aromatic hydrocarbons emitted from plastic waste recycling plants. Chemosphere 74(8):1104-1110. https://doi. org/10.1016/j.chemosphere.2008.10.041

Villberg K, Veijanen A (2001) Analysis of a GC/MS Thermal desorption system with simultaneous sniffing for determination of off-odor compounds and VOCs in fumes formed during extrusion coating of low-density polyethylene. Anal Chem 73(5):971-977. https://doi.org/10.1021/ac001114w

Willoughby BG, Golby A, Davies J, Cain R (2003) Volatile component analysis as a routine characterisation tool: an approach to fingerprinting polyolefin type and process history using ATD-GC/ MS. Polym Test 22(5):553-570. https://doi.org/10.1016/s0142 -9418(02)00152-6

Wolkoff P (1998) Impact of air velocity, temperature, humidity, and air on long-term voc emissions from building products. Atmos Environ 32(14-15):2659-2668. https://doi.org/10.1016/s1352 $-2310(97) 00402-0$
Yang H, Yan R, Chen H, Zheng C, Lee DH, Liang DT (2006) In-depth investigation of biomass pyrolysis based on three major components: hemicellulose, cellulose and lignin. Energ Fuel 20(1):388393. https://doi.org/10.1021/ef0580117

Yu C, Crump D (1998) A review of the emission of VOCs from polymeric materials used in buildings. Build Environ 33(6):357-374. https://doi.org/10.1016/s0360-1323(97)00055-3

Zabiegała B, Partyka M, Gawrońska A, Wasilewska A, Namiesnik J (2007) Screening of volatile organic compounds as a source for indoor pollution. Int J Environ Health 1:13-28. https://doi. org/10.1504/IJENVH.2007.012222

Zdrahala RJ, Zdrahala IJ (1999) Biomedical applications of polyurethanes: a review of past promises, present realities, and a vibrant future. J Biomater Appl 14:67-90. https://doi.org/10.1177/08853 2829901400104

Publisher's Note Springer Nature remains neutral with regard to jurisdictional claims in published maps and institutional affiliations. 